\title{
Clinical Implications of Treating Female Genital Mutilation: Psychological Aftermath
}

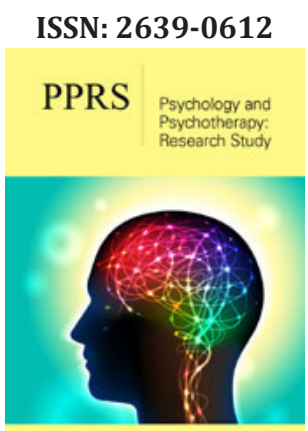

*Corresponding author: Farah Nadeem, Department of Psychologist, United Kingdom

Submission: 枈 January 22, 2019

Published: 想 October 23, 2019

Volume 2 - Issue 5

How to cite this article: Farah Nadeem. RClinical Implications of Treating Female Genital Mutilation: Psychological Aftermath. Psychol Psychother Res Stud. 2(5).PPRS.000548.2019.

DOI: 10.31031/PPRS.2019.02.000548

Copyright@ Farah Nadeem, This article is distributed under the terms of the Creative Commons Attribution 4.0 International License, which permits unrestricted use and redistribution provided that the original author and source are credited.

\author{
Farah Nadeem* \\ Department of Psychologist, United Kingdom
}

Opinion

This two-page review is about the issues psychologist/therapist experience when treating Female genital mutilation (FGM). This research was composed by the experiences of mental health practitioners. FGM is considered a form of child abuse (NSPCC, 2018), the difference from other forms of trauma is the perpetrators are the mothers. FGM has been illegal in the UK since 1985 and is punishable by up to 14 years in prison. With an increase in migration to the UK of people who still practice this horrific custom, FGM has become more prevalent in the UK and it is estimated that approximately 137,000 women and girls have been victims of the practice. Around the globe, 130 million girls and women have undergone FGM (World Health Organisation (WHO, 2014). In Africa, 101 million girls aged 10 and over have been subjected to FGM (WHO, 2014). Every year a further 3 million girls are at risk of FGM in Africa alone (WHO, 2014), amounting to almost 5,500 each day.

The aim of this article is to explore the experience of therapists working with clients who have suffered FGM in childhood; with the view to both informing future practice with such clients and offering information to those without experience of working with FGM. This book showed a greater understanding of the experience of therapists working with clients who have suffered FGM in childhood, such as psychological impact in the work, the clinical implications and the cultural dynamics that occur in the work. Therapist made Suggestions as to how future practices and guidelines can be adapted to better reflect such experience. For example, this was done by therapist reflecting on experiences of vicarious trauma, issues to mindful of such as being more psycho-educated, being more open and providing clients a safe place by listening to the client's narratives and further being aware that each case is different. So, if one therapeutic modality worked for one FGM survivor that may not be the case for another, thus substantiating an idiosyncratic approach when working with FGM survivors. This research also provided a clearer understanding of problematic elements of working with FGM in the therapeutic relationship, such as issues with trust and privacy, the legislative element of the work such as naming it as child abuse and issues with possible risk when working with FGM clients.

Implications for Clinical Practice for the Discipline of Counselling Psychology

\section{Empathize ways of facilitating understanding between therapist and FGM survivors}

1. Consideration of the language constructs clients use in meaning making of their trauma.

2. Understanding the cultural context of the practice.

3. Awareness of terminology use: avoiding language that isolates survivors such as references of the procedure being known as child abuse.

4. The use of legislation in a harmonious approach, being sensitive and thoughtful regarding issues of safeguarding.

\section{Managing emotions and developing increased self-awareness as therapist}

1. Understating the parallel processes within the work. 
2. Developing appropriate strategies of unwanted thoughts and emotions (VT, STS, burnout, ountertransference, disengagement, frustrations).

\section{Gaining appropriate self-care strategies}

\section{Therapeutic effectiveness within FGM client work}

1. By developing increased personal awareness to enhance therapeutic relationship.

2. Engaging empathetically with FGM survivors, while ensuring that appropriate boundaries have been maintained and emotional observing is ongoing.

3. Continue professional development for training about the FGM procedure and training in trauma work.

This research could be deemed as Informing the development of therapeutic formulations and conceptualizations of working with violence against women, FGM survivors. The key finding in conceptualization is understanding the context of this act and providing a safe place where the therapist actively listens by providing therapy or assessment in an idiosyncratic manner. In addition, this research could provide insight to the application of relational theory to better represent work with this client group for example emphatic encounters that led to therapist vicarious trauma. As this is small review of my findings from my book named 'FGM: practitioners guide to treating Female genital mutilation', [1] you can find more information regarding the psychological aftermath of FGM.

\section{References}

1. Nadeem F (2018) FGM: A practitioner's guide to treating female genital mutilation. Blurb, London, United Kingdom. 